\title{
ACTIVIDAD TORMENTOSA, MARITIMA, LITORAL Y MICROCONTINENTAL EN ÁMBITOS INSULARES. UN ANÁLISIS GEOGRÁFICO APLICADO A MALLORCA
}

\author{
Miquel Tomàs-Burguera \\ Miquel Grimalt Gelabert \\ Departamento de Ciencias de la Tierra. Universitat de les Illes Balears \\ miquel.tomas@gmail.com
}

\section{RESUMEN}

Se analiza la distribución espacio-temporal de las descargas eléctricas nube-tierra en Mallorca y su mar circundante entre 2000 y 2011, obteniendo una elevada irregularidad interanual, con un máximo de actividad concentrado a finales de verano.

Se detectan factores de distribución territorial derivados de la latitud, la topografía y las convergencias de vientos locales, sin apreciarse un patrón derivado de los usos del suelo.

La zona marítima y la terrestre presentan una densidad espacial de descargas similar, pero una distribución horaria contrastada, detectándose un gradiente en función de su posición respecto a la costa, con un máximo nocturno en alta mar y uno diurno en el interior de Mallorca.

Palabras clave: Mallorca, descargas eléctricas, costa, distribución horaria.

\section{ABSTRACT}

Spatial and temporal distribution of cloud to ground lightning strokes in Mallorca and its surrounding sea is analyzed for the period 2000-2011. A high interannual variability is detected, with a remarkable maximum at the end of the summer.

Latitude, topography and local winds convergence are detected to affect the spatial distribution. Instead, land cover seems not to influence.

Fecha de recepción: octubre 2012.

Fecha de aceptación: octubre 2013. 
With a similar spatial density, maritime are and terrestrial area differ significantly in its hourly distribution. In fact, a gradient based on the position in relation to the shore is appreciated, with a nocturnal maximum over the sea and a diurnal maximum in the inner of Mallorca.

Key words: Mallorca, lightning strokes, shoreline, hourly distribution.

\section{INTRODUCCIÓN}

Las descargas eléctricas suponen el rasgo definitorio de las tormentas, y al mismo tiempo implican un riesgo natural de notable impacto. Aunque es frecuente que junto con las descargas eléctricas aparezcan otros fenómenos naturales adversos, como las lluvias intensas o fuertes rachas de viento, en el presente estudio se analizarán únicamente las descargas eléctricas.

Durante una tormenta se pueden producir 2 tipos distintos de descargas eléctricas, las nube-tierra y las nube-nube. Las primeras se caracterizan por impactar en la superficie terrestre (ya sea continental u oceánica), mientras que las segundas se producen en el seno de una misma nube o entre dos nubes próximas. A priori, las descargas que suponen un mayor riesgo para las actividades humana son las nube-tierra, ya que la afectación derivada de las nube-nube aparece restringida a impactos en aeronaves.

Aunque en muchas ocasiones se tratan como sinónimos rayos y descargas eléctricas, se trata de dos fenómenos distintos. El rayo es el canal que se establece entre la nube y la superficie terrestre por el cual circula la carga eléctrica y que puede vehicular una o varias descargas. La percepción visual humana es incapaz de distinguir claramente las distintas descargas que se producen en un mismo rayo (Christian y McCook).

Una descarga eléctrica que impacta en tierra supone un fenómeno eléctrico de elevada intensidad (se mide en kiloamperios) y, por lo tanto, puede provocar importantes daños en el punto de impacto y sus proximidades. Existen ámbitos, tanto temporales como espaciales, que resultan más propensos a recibir rayos. De hecho, para la isla de Mallorca, diversos análisis señalan que el final de la época cálida del año supone el momento con mayor número de descargas eléctricas, y la parte norte de la isla el lugar con mayor densidad de las mismas. (González Márquez, 1996; Guijarro y Heredia, 2004; Ruiz et al 2012).

En un contexto planetario, los estudios demuestran que la superficie terrestre sólida recibe la mayoría de impactos, mientras que sólo una minoría impacta en la superficie oceánica. Así, para el período comprendido entre el 4 de mayo de 1995 y el 21 de marzo de 2000, Christian et al (2003) obtienen una ratio de 10:1 en favor de las zonas terrestres. Sin embargo, en el ámbito mediterráneo, análisis como el realizado por Altaratz et al (2003) en Israel obtienen proporciones más igualadas, de 1,64:1.

El contraste de actividad eléctrica entre el ámbito continental y el oceánico no se restringe únicamente al número absoluto de descargas, sino que también se aprecian contrastes marcados en cuanto a su distribución temporal (Blakeslee et al 2012).

Williams y Chan (2004), a partir del estudio de las descargas eléctricas en distintas islas del ámbito tropical, establecen el límite superficial a partir del cual los espacios terrestres presentan una actividad eléctrica contrastada respecto a su océano circundante y lo sitúan en 
un valor en el orden de magnitud de $10^{2}$ a $10^{3} \mathrm{~km}$. La isla de Mallorca aunque no se encuentra en un ámbito geográfico de referencia del estudio anteriormente citado, sí que presenta una extensión superior a este límite, con $3.620,02 \mathrm{~km}^{2}$.

El objetivo del presente estudio es comprobar si en el ámbito de estudio constituido por la isla de Mallorca y su mar circundante el contraste entre la actividad eléctrica tierra/océano se ajusta a los patrones descritos en otras regiones. Dada la extensión del área insular se puede presumir algún tipo de contraste que, dadas las condiciones latitudinales y de entorno geográfico, se espera se ajusten más a los resultados obtenidos por Altaratz et al (2003) que no a los señalados por Christian et al (2003).

Se ha puesto especial énfasis en el estudio de las descargas eléctricas producidas en la zona de transición que supone la franja litoral, con el fin de caracterizar con precisión la distancia a la línea de costa en la que se produce el cambio de comportamiento entre la actividad tormentosa típicamente terrestre y la típicamente marítima.

El análisis especial se complementa con una aproximación a la relación de los usos del suelo y la topografía con las descargas eléctricas.

\section{DATOS Y METODOLOGÍA}

Se ha acotado el área de estudio (Figura 1) a la isla de Mallorca y la franja marítima de $20 \mathrm{~km}$ alrededor de la misma. Se ha elegido este rango ya que supone conseguir que ningún punto estudiado, independientemente de su carácter marítimo o insular, esté a una distancia superior aproximada de $20 \mathrm{~km}$ a la línea de costa. Se analiza, por tanto una superficie total de $10.652,79 \mathrm{~km}^{2}$, de los cuáles $3.620,02 \mathrm{~km}^{2}$ corresponden a la isla y $7.032,77 \mathrm{~km}^{2}$ superficie oceánica.

Topográficamente la isla de Mallorca presenta notables diferencias de relive: las máximas elevaciones se concentran en la Serra de Tramuntana, con alturas en su sector central superiores a los 1000msnm, siendo el Puig Major, con 1445m, el punto más elevado. Fuera de la cordillera septentrional destacan las elevaciones asociadas a las Serres de Llevant, ubicadas en el este de la isla, con altitudes máximas entorno a 500m. Entre ambos sistemas montañosos existe una región relativamente llana, aunque con presencia de colinas con elevaciones entorno a 200-300m. Dentro de esta región se individualiza el Puig de Randa, que con sus $543 \mathrm{~m}$ se convierte en el punto más alto fuera de los dos sectores de relieves alineados. La forma de la isla es aproximadamente romboidal, sin promontorios remarcados, a excepción del Cap Formentor y del Cap des Pinar situados en el extremo NE. De modo que ningún punto de la isla se encuentra alejado más de $25 \mathrm{~km}$ de la línea costera.

Los datos de las descargas eléctricas nube-tierra se han obtenido de la red de detección de rayos de la Agencia Estatal de Meteorología (AEMET), que ubica temporal y geográficamente las mismas, aunque no considera las nube-nube. Esta red empezó su funcionamiento en 1992 (Pérez-Puebla, 1999). En el presente trabajo analiza únicamente el período 2000-2011, ya que en el año 2000 hubo cambios en el sistema de detección que mejoraron sensiblemente su fiabilidad. Además, los datos recogidos a partir del 2000 se demuestran homogéneos para estudios climáticos (López Díaz et al 2012), cosa que no sucede con los anteriores. Cabe recordar que al tratarse de descargas y no de rayos pueden darse coincidencias espaciotemporales entre las mismas. 


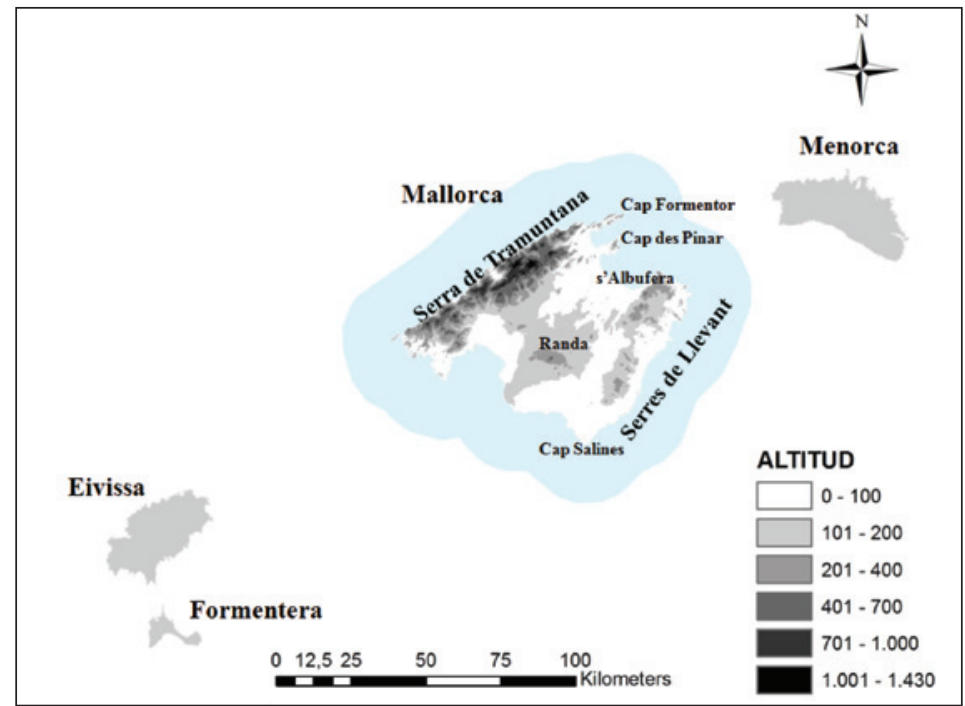

Para llevar a cabo el análisis de las descargas eléctricas, el contraste entre la zona marítima y terrestre, y las relaciones de las descargas con los usos del suelo y la topografía se ha hecho uso de Sistemas de Información Geográfica (SIG), concretamente de ArcGIS 10 y gvSIG 1.11.

Además de los datos de las descargas eléctricas ha sido necesario contar con otras capas de información, como las curvas de nivel de la isla de Mallorca y las informaciones sobre usos del suelo del año 2006 siguiendo la clasificación de Corine Land Cover, que se han usado a la hora de realizar el análisis de la información.

Figura 2

TRATAMIENTO DE LOS DATOS

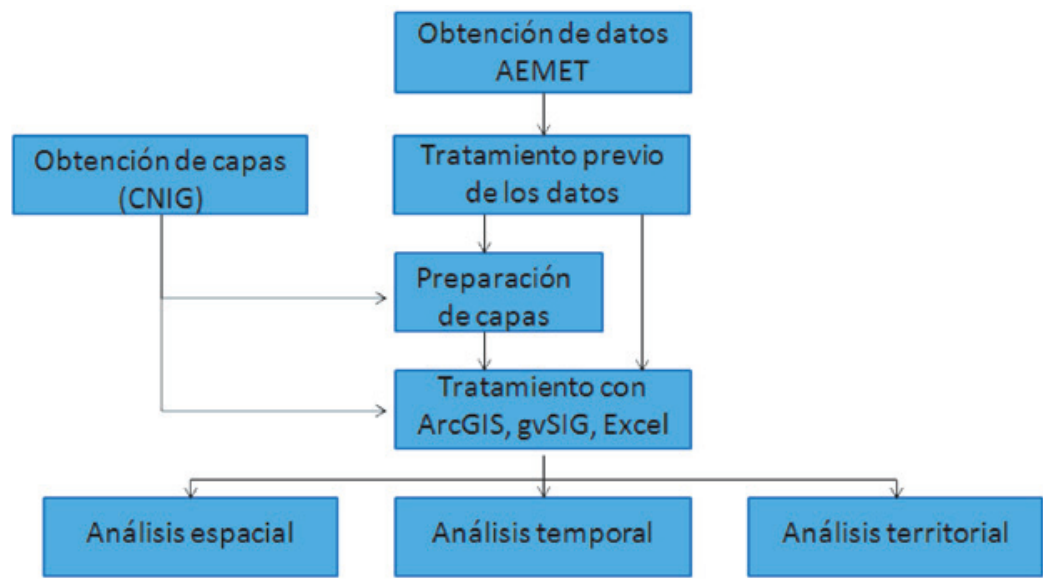


Además, usando como base la curva de nivel de 0 metros, se han creado diferentes ámbitos de estudio (tanto marítimos como terrestres) limitados por líneas paralelas a la línea de costa (buffers), siendo las distancias elegidas 1, 2, 5, 10 y 15km (Figura 3). Para la zona marítima se crea un buffer adicional a 20km de distancia, que es el límite exterior absoluto del área de estudio.

Figura 3

BUFFERS CREADOS EN LA ZONA DE ESTUDIO A PARTIR DE LA LÍNEA COSTERA

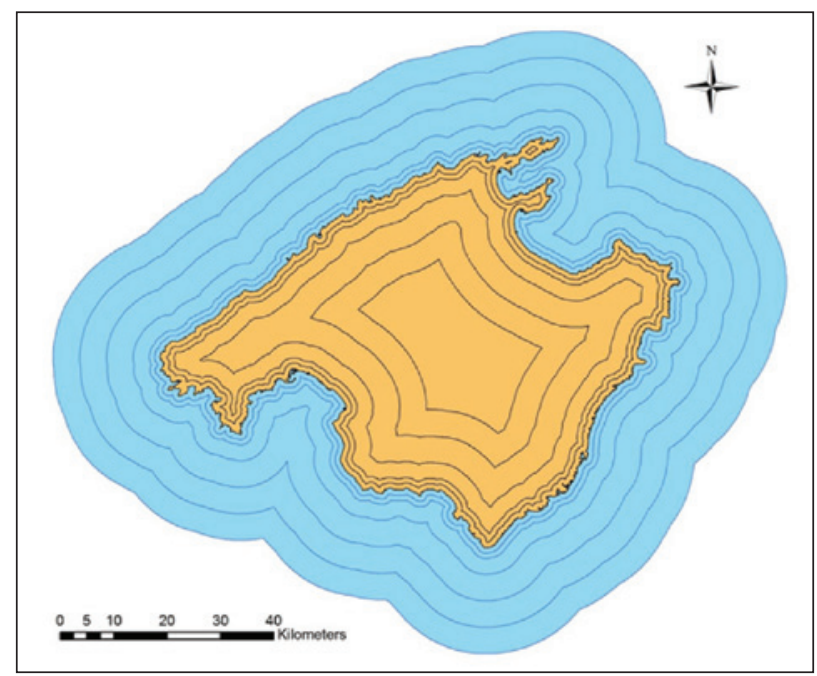

Fuente: Elaboración propia.

A la hora de realizar el análisis, se incide tanto en la distribución geográfica como temporal del fenómeno y el análisis de los resultados obtenidos se ha organizado en tres apartados principales, que hacen referencia a los parámetros espaciales genéricos del fenómeno (I), a sus parámetros temporales (II) y a sus relaciones con las distintas franjas creadas (III).

\section{RESULTADOS Y DISCUSIÓN}

\subsection{Parámetros espaciales}

En el conjunto de la región de estudio se han detectado (2000-2011) un total de 318.763 descargas eléctricas, de las cuales 106.993 impactaron en la isla de Mallorca, mientras que el resto, 211.770, lo hicieron en la zona marítima. Esta actividad eléctrica se concentró en un total de 964 días de tormenta (representando un 21,9\% de las jornadas sobre el total de 4.383), con 720 días en el interior de la isla y 889 días en el área marítima. Ello se traduce en una densidad media de 2,49 descargas $/ \mathrm{km}^{2} /$ año, siendo la misma de 2,46 descargas $/ \mathrm{km}^{2} /$ año para la superficie insular y 2,51 descargas $/ \mathrm{km}^{2} /$ año para la marítima con una distribución irregular en el territorio analizado (Figura 4). Se obtiene así una proporción tierra-mar 0,98:1, muy lejos del valor 10:1 obtenido globalmente (Christian et al 2003), y más próxima a la obtenida por Altaratz et al (2003) de 1,64:1 en la zona de Israel. 
Los valores máximos de densidad de descargas se alcanzaron en el norte de la isla y en la zona marítima próxima, con valores claramente por encima de la media. Hay algunos enclaves que presentan registros ligeramente superiores a 11 descargas $/ \mathrm{km}^{2} / \mathrm{año}$, alrededor de las cimas más elevadas de la Serra de Tramuntana y en el promontorio del Cap Formentor.

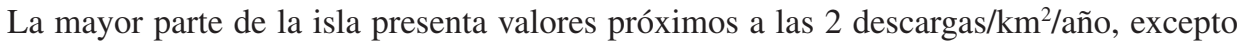
un eje que se constituye en el interior de la misma, coincidiendo prácticamente con una línea de simetría con dirección NW-SE, con valores máximos entorno a las 4 descargas $/ \mathrm{km}^{2} / a n ̃ o$. Dicho eje se prolonga sobre el mar frente al litoral de levante, que coincide aproximadamente con la zona de afectación de las tormentas por convergencia de brisas, que en la parte cálida del año se producen preferentemente en puntos del interior de Mallorca (Alomar, 2012; Alomar y Grimalt, 2009; Ramis, 1998).

En el extremo occidental del área de estudio también aparecen distintos núcleos de máxima actividad, localizados en la zona marítima.

Por lo que respecta a los valores mínimos, éstos se localizan en el sur y sureste de la zona de estudio, con amplias zonas de valores inferiores a 2 descargas $/ \mathrm{km}^{2} /$ año, con lo que se detecta un gradiente latitudinal de fondo en la actividad eléctrica, con los valores máximos al norte y los mínimos al sur. Este hecho seguramente está ligado a la proliferación de situaciones atmosféricas en que la inestabilidad más importante queda restringida en la mitad septentrional de la cuenca Mediterránea Occidental, en estas circunstancias las tormentas solamente afectan al norte del área de estudio, o bien presentan su mayor actividad en ese ámbito. También se puede señalar, que parte de esta actividad podría estar ligada a la convergencia de vientos catalano-balear, por la cual en entradas de viento de componente norte la tramontana y el cierzo confluyen en el área comprendida entre la costa nororiental de Mallorca y el litoral occidental de Menorca (Pascual y Callado, 2002)

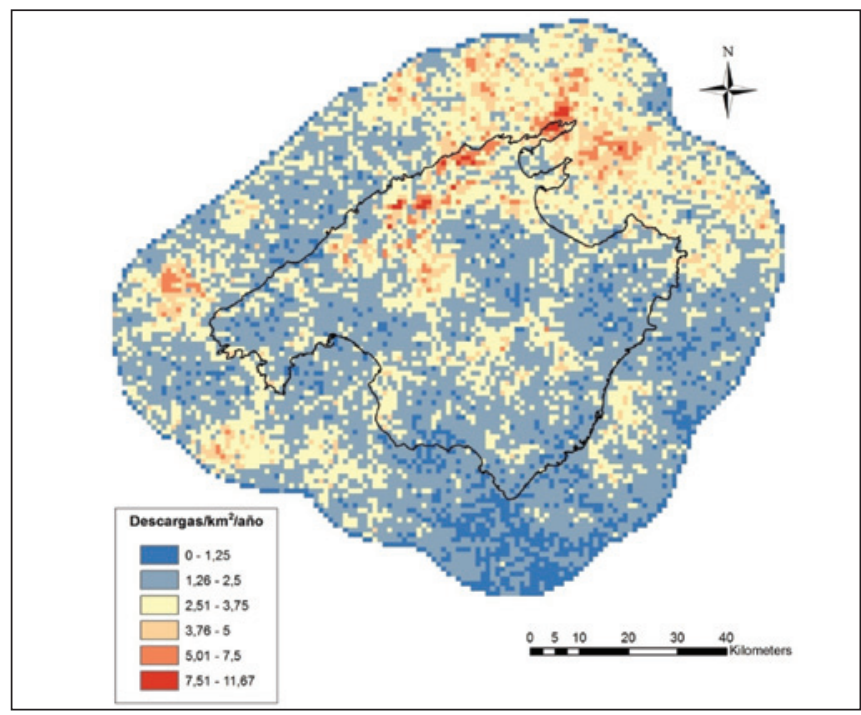




\subsection{Parámetros temporales}

Se ha analizado la distribución interanual, mensual y horaria de las descargas eléctricas en el conjunto del área de estudio, introduciendo la diferenciación entre el área marítima y terrestre.

\subsubsection{Parámetros interanuales}

La distribución interanual de las descargas eléctricas a lo largo de los 12 años de observación (Figura 5.a) presenta una elevada irregularidad, de tal manera que para una media de 2,49 descargas $/ \mathrm{km}^{2} / a$ ño, su desviación estándar es de 1,04 descargas $/ \mathrm{km}^{2} / a n ̃ o$. Esta irregularidad, presente tanto en la zona marítima como en la terrestre, también se manifiesta en el propio contraste entre ambas zonas, de manera que se suceden años con actividad superior en tierra y otros en el mar concentra una mayor actividad tormentosa.

Afectando tanto a la zona marítima como terrestre, el año con una mayor número de descargas es el 2009 y el menos tormentoso es el 2010, único en donde manteniéndose la pauta de distribución territorial de la densidad no se alcanzan las 10.000 descargas.

Figura 5

DISTRIBUCIÓN INTERANUAL DE LAS DESCARGAS ELÉCTRICAS Y LOS DÍAS DE TORMENTA

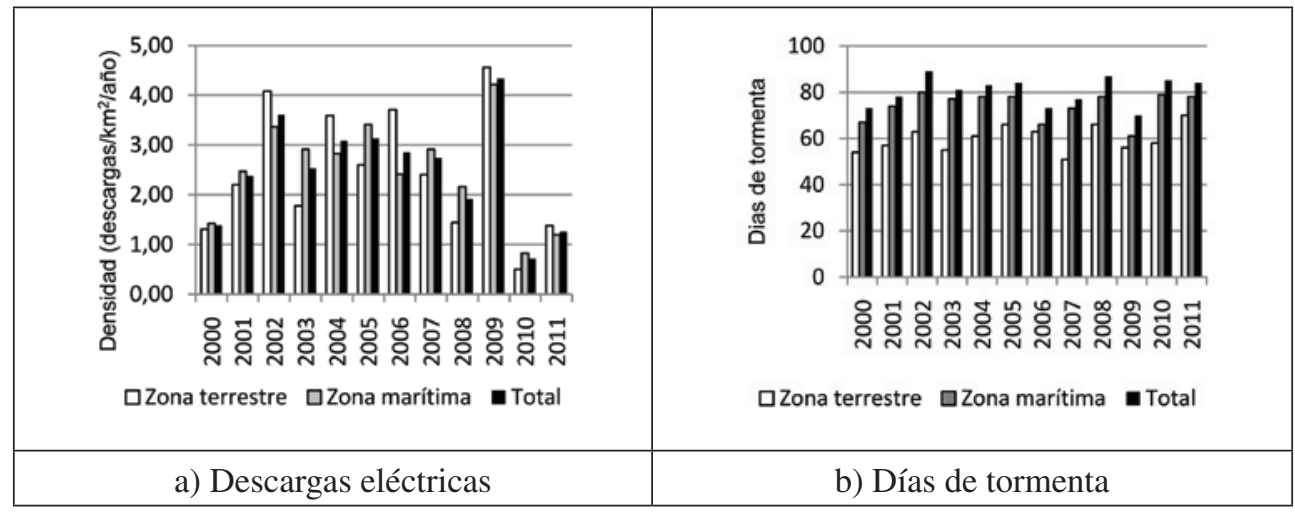

Fuente: Elaboración propia a partir de datos AEMET

En cambio, los días de tormenta (Figura 5.b) presentan una variabilidad mucho menos destacada, con una gran regularidad entre un año y otro, de modo que, para una media de 80,3 días, la desviación estándar es de 6,08 días. Además, en ninguno de los años ha habido menos de 70 jornadas tormentosas ni más de 90 .

La mayor regularidad interanual del número de días de tormenta frente al de descargas eléctricas hace suponer que las condiciones atmosféricas necesarias para el desarrollo de tormentas se dan con bastante regularidad un año tras otro, pero que existen episodios especialmente virulentos que concentran un número muy elevado de descargas, y que tienen elevada influencia en la irregularidad interanual de las mismas. 


\subsubsection{Parámetros mensuales}

En los estudios realizados hasta el momento para el área de Baleares se ha determinado el mes de septiembre como mes con mayor actividad eléctrica (González Márquez, 1996; Guijarro y Heredia; 2004, Ruiz et al, 2012), hecho que de nuevo se confirma en el presente análisis. De hecho, el porcentaje de actividad en este mes es ampliamente superior al del resto de meses, suponiendo un $41 \%$ de las descargas en la zona terrestre y un valor ligeramente superior, próximo al 50\%, para la zona marítima. Además, en ambos casos el total de descargas para el trimestre agosto, septiembre, octubre supone un valor del $75 \%$, correspondiéndose con el final de la época cálida, y por lo tanto, la época en que son posibles los máximos desarrollos verticales. De hecho, es el único mes que presenta una actividad media superior a $1 \mathrm{descarga} / \mathrm{km}^{2} / \mathrm{año}$, tanto para la superficie terrestre como para la marítima (Figura 6.a).

Para algunas zonas continentales del mismo hemisferio, analizadas por diversos autores, el máximo de actividad suele concentrarse en los meses de julio y agosto, así se detecta en Georgia, Estados Unidos (Bentley y Stallins, 2005) y en la mayoría de zonas terrestres (Christian et al 2003). Sin embargo, en la zona de la Península Ibérica este máximo aparece desplazado hacia los meses de agosto y septiembre (Rivas Soriano et al 2005) y en el entorno de la isla de Mallorca (tanto en su zona marítima como terrestre) se concentra en el mes de septiembre (Figura 6). Mientras que en las zonas estrictamente continentales, el máximo de actividad se puede ligar casi exclusivamente a los momentos de máximo calentamiento diurno, el máximo del mes de septiembre en Mallorca se asocia principalmente a la combinación entre elevadas temperaturas de la superficie marítima y la llegada de las primeras irrupciones de aire frío. Dicha combinación también explica la gran actividad del trimestre agosto-septiembre-octubre.

En cambio, los meses invernales, cuando se alcanzan los valores mínimos de temperatura, son los que presentan una menor actividad eléctrica, con porcentajes que algunos meses están por debajo del $1 \%$ sobre el total anual, dando lugar a densidades prácticamente imperceptibles (Figura 6.a). Aunque la pluviometría en Mallorca de diciembre a febrero es relativamente abundante, las precipitaciones generalmente no vienen acompañadas de una gran actividad eléctrica debido a que la estructura invernal de la atmosfera, con unas temperaturas superficiales inferiores y una tropopausa situada a menor altitud, no favorece el crecimiento de nubes con tanto desarrollo vertical.

La transición entre el mínimo invernal y el máximo de finales de verano se da de manera gradual hasta el mes de julio, cuando el porcentaje de la actividad alcanza proporciones entorno al 4\% de la actividad anual. En tanto que el incremento de actividad intermensual entre julio-agosto y agosto-septiembre es muy importante

Por lo que concierne al contraste entre la zona marítima y la terrestre, la densidad de descargas en tierra es superior para el período marzo-agosto, mientras que de septiembre a febrero es mayor en la zona marítima. El hecho de que el período marzo-agosto presente mayor actividad en tierra enlaza con las condiciones de mayor calentamiento diurno de la superficie terrestre respecto a la marítima, así como por la presencia del embat (brisa marina) y su zona de convergencia asociada en el interior de la isla, que en determinadas circunstancias favorece el crecimiento de núcleos tormentosos. 


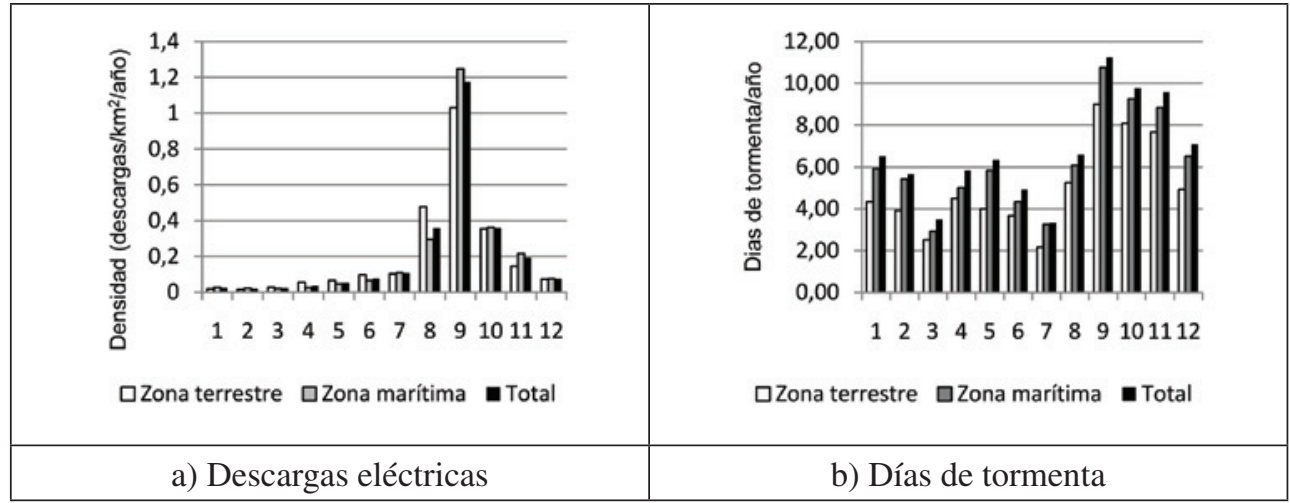

Fuente: Elaboración propia a partir de datos AEMET

A simple vista, la distribución de los días de tormenta difiere significativamente respecto a la distribución de las descargas eléctricas. Si bien es cierto que el mes de setiembre se presenta de nuevo como el que presenta una mayor actividad, su grado de concentración (en torno a un $15 \%$ de la actividad anual con poco más de 10 días de tormenta al año) es mucho menor que en el caso de las descargas. Además, el trimestre más activo se desplaza un mes, y pasa a estar conformado por el setiembre-octubre-noviembre.

La parte cálida del año es propensa a generar un mayor número de descargas en cada episodio que la parte fría del año. Este hecho, achacable al mayor desarrollo de las nubes en la época cálida, es el que explica la diferencia significativa que se observa en septiembre, que concentra el $15 \%$ de los días de tormenta del año, pero el $45 \%$ de las descargas.

Otro cambio importante es el de los valores mínimos, que en el caso de días de tormenta tiene lugar en los meses de marzo y julio. El mínimo de marzo podría estar ligado al mínimo anual de temperatura del mar, que tiende a estabilizar la atmosfera, mientras que el mínimo de julio se corresponde con la estabilidad veraniega, que alcanza su cénit en este mes.

\subsubsection{Parámetros horarios}

La distribución horaria (Figura 7) presenta una oscilación de las descargas a lo largo del día con dos momentos de máxima actividad, uno concentrado durante las horas centrales de la jornada y otro durante la madrugada. Mientras que el máximo diurno, centrado en las 13UTC, se corresponde sobretodo con actividad terrestre, el máximo nocturno, centrado en las 02UTC, se localiza en la zona marítima. Destaca que la zona terrestre presenta un máximo secundario en las horas nocturnas, mientras que la zona marítima también presenta un máximo secundario en torno a las horas centrales del día, quedando las últimas horas de la madrugada y las primeras horas de la tarde como momentos de mínima actividad en ambos territorios. 
El máximo de actividad terrestre durante las horas centrales del día tiene su influencia en las precipitaciones de la isla de Mallorca, que, sobre todo durante la época cálida, presentan una elevada proporción de las mismas durante esas mismas horas. (Guijarro, 2012)

Si se compara este patrón con el detectado por otros estudios se observan semejanzas, aunque en zonas continentales, como la Península Ibérica (Rivas Soriano et al 2005) o el oeste de Francia (Seity et al, 2000) la actividad máxima suele aparecer a las últimas horas de la tarde, cuando el calentamiento diurno alcanza su máximo valor, y por lo tanto, se logra así una máxima energía potencial disponible para el crecimiento de las nubes convectivas (William et al, 2000).

Sin embargo, en la época cálida del año la temperatura de la isla de Mallorca está regulada por el embat (nombre local que recibe la brisa marina), que provoca que el máximo de temperatura se encuentre desplazado hacia el mediodía en lugar de a media tarde (Alomar, 2012). Por lo tanto, es hacia las 12 UTC cuando la energía disponible para el crecimiento de tormentas es mayor. Además, el régimen de brisas se caracteriza por presentar distintos puntos de convergencia, que en determinadas situaciones actúa de mecanismo de disparo para el crecimiento de tormentas (Alomar, 2012;Alomar y Grimalt, 2009;Ramis, 1998). Ambos factores son los que explican el horario adelantado del máximo diurno de actividad tormentosa en Mallorca respecto a las zonas continentales.

Durante las horas nocturnas la actividad marítima tiende a ser más importante que la actividad terrestre, ya que la mayor inestabilidad durante esas horas se localiza sobre el mar, al tener una temperatura superficial más elevada que la de la zona terrestre, debido a su mayor inercia térmica.

Las 23UTC y las 00UTC suponen una anomalía a este hecho, ya que en este lapso de tiempo, la actividad eléctrica es más importante en tierra que en el mar. Otra anomalía menor detectada es el desplome en la actividad eléctrica de la zona terrestre que se manifiesta a las 02UTC, y que si bien sigue con la tendencia de descenso de actividad en ese entorno geográfico, supone una anomalía respecto a los valores de las 01UTC y las 03UTC.

DISTRIBUCIÓN HORARIA DE LA DENSIDAD DE DESCARGAS ELÉCTRICAS

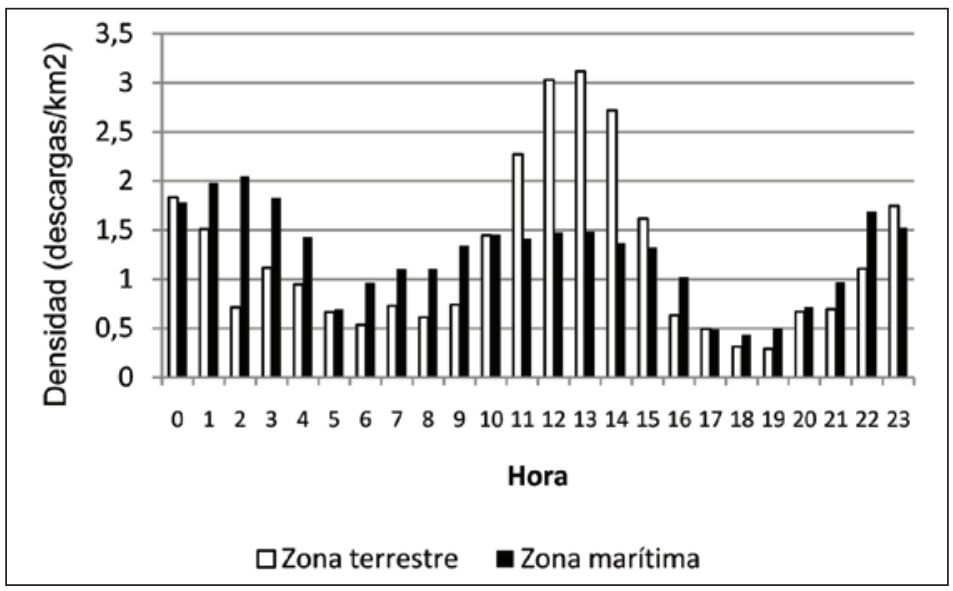

Fuente: Elaboración propia a partir de datos de AEMET 


\subsection{Parámetros geográficos}

\subsubsection{La distancia a la línea litoral (análisis de buffers)}

Además de la simple diferenciación entre la actividad terrestre y la marítima se ha realizado un análisis exhaustivo sobre el conjunto de franjas definido en la figura 2, con el objetivo de determinar, si es posible, la zona de ruptura entre la actividad típicamente terrestre y la marítima.

Las características de la actividad registrada en las franjas marítimas y terrestres situadas a una distancia inferior a $10 \mathrm{Km}$ a la línea de costa es bastante similar, con independencia de que se trate de tierra o mar. Al superarse este, ambas zonas presentan diferencias notables, con un incremento notable de la actividad diurna en tierra y un leve repunte de la nocturna en la zona marítima.

A medida que abandonamos la línea de la costa para adentrarnos en Mallorca (Figura 8.a) el máximo de actividad diurno incrementa su peso específico, siendo este aumento notable en los sectores alejados 10km o más del Mediterráneo. En cambio, a la actividad nocturna le sucede lo contrario, ya que su importancia relativa va disminuyendo de forma paulatina hacia el centro de la isla.

Además, el máximo de actividad diurno padece un desplazamiento horario, de tal manera que si en las zonas más próximas a la costa se presenta entre las 13 y las 14UTC, en tanto que en el interior de la isla se adelanta su aparición, hasta tal punto que en el sector central de Mallorca la máxima actividad se concentra a las 12 UTC, acumulando un total del $18,69 \%$ de la actividad diaria en esa misma hora y hasta un 56\% para el periodo que va de las 10UTC a las 14UTC. Lo cual corrobora más la hipótesis que lo relaciona con la convergencia de brisas.

Respecto a la anomalía detectada en la actividad eléctrica a las 02UTC ésta aparece en todas las franjas terrestres. Sin embargo, su importancia disminuye a medida que nos adentramos en la zona terrestre.

Por lo que se refiere a las franjas marítimas se detecta que a medida que nos adentramos en el mar la actividad nocturna va incrementando su peso relativo (Figura 8.b), aunque no de manera tan importante como lo hace la actividad diurna en la zona terrestre. Este ligero incremento en el porcentaje de la actividad nocturna se manifiesta de manera más importante a partir de los $10 \mathrm{~km}$ de distancia a la costa, punto a partir del cual la actividad nocturna presenta puntas superiores a la actividad diurna, concentrando valores superiores al $30 \%$ para el período 00UTC a 04UTC, mientras que para el período 10UTC a 14UTC se queda por debajo del $25 \%$.

Para las zonas más próximas a la costa, el máximo de actividad nocturna se centra en las 01UTC, mientras que en las zonas más alejadas este máximo aparece centrado en las 02UTC (Figura 8.b). A pesar de presentar este máximo de actividad, esta zona presenta un menor contraste entre horas que la zona terrestre.

Por lo que respecta al mínimo de actividad, en ambas zonas (marítima y terrestre) se centra entre las 17 y las 19UTC. Mientras que en las zonas más próximas a la costa el mínimo tiende a estar centrado a las 19UTC, en las zonas más alejadas (tanto del interior de Mallorca como de la zona marítima) éste se da una o dos horas antes. 

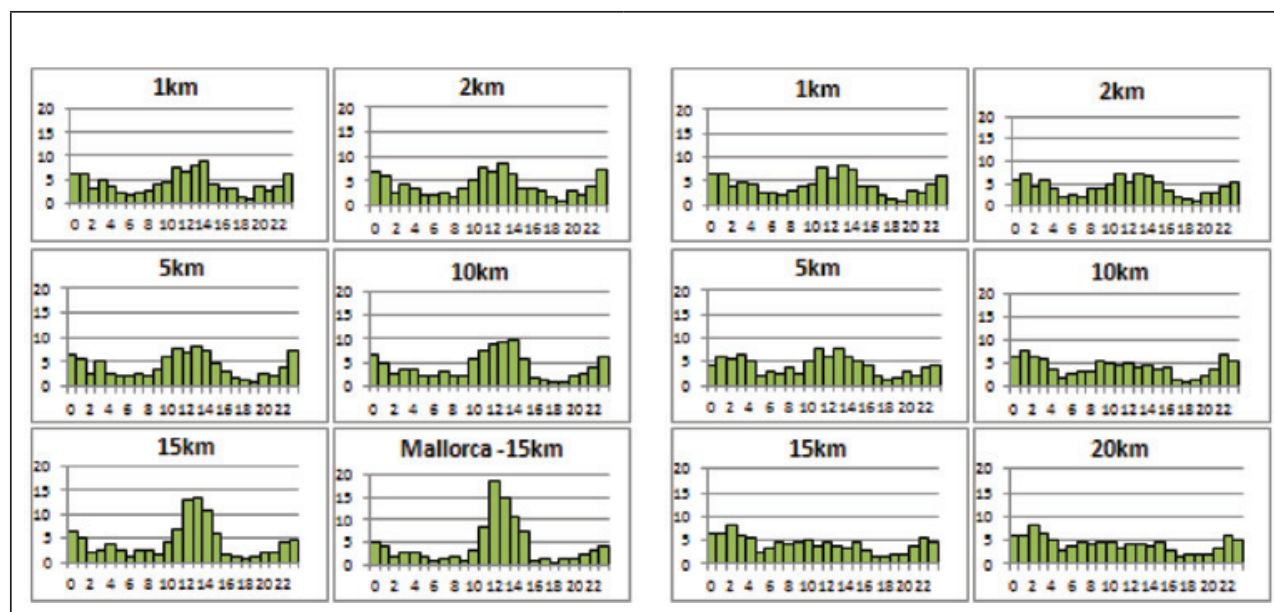

a) Buffers terrestres.

b) Buffers marítimos.

Fuente: Elaboración propia a partir de datos de AEMET

Figura 9

DISTRIBUCIÓN MENSUAL DE LAACTIVIDAD ELÉCTRICA EN LOS DISTINTOS BUFFERS DEL ÁREA TERRESTRE (a) Y MARITIMA (b)
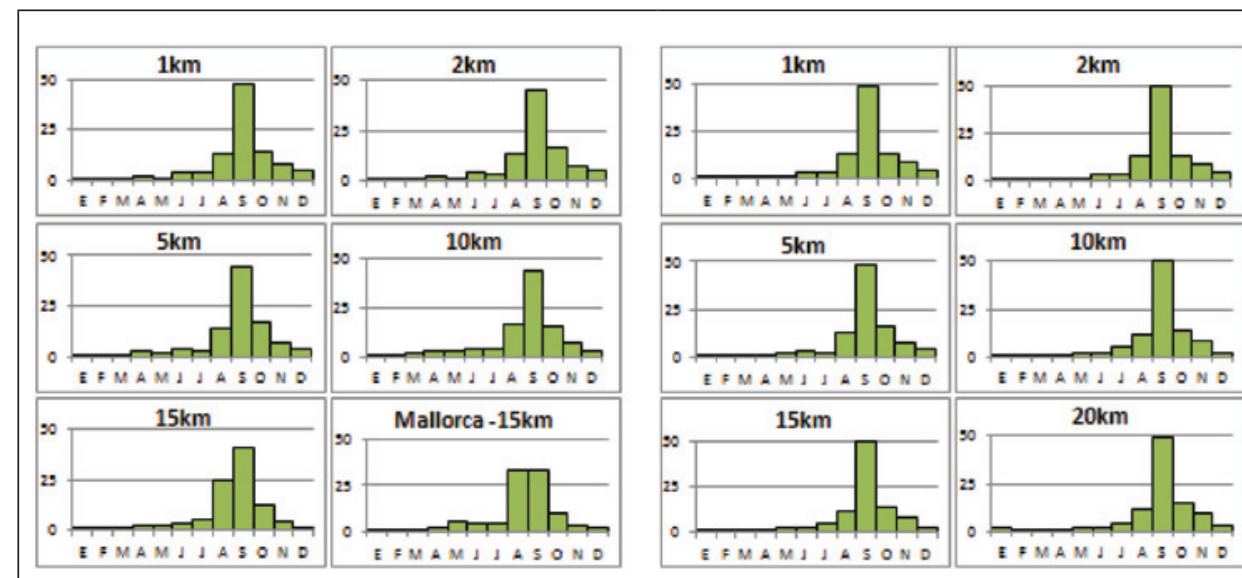

a) Buffers terrestres

b) Buffers marítimos

Fuente: Elaboración propia a partir de datos de AEMET 
Analizando la distribución mensual en relación a la distancia a la costa se detecta que el mes de septiembre (al igual que sucedía para el conjunto del área de estudio) es el que presenta una mayor concentración de la actividad eléctrica. Sin embargo, a medida que nos adentramos en la isla su peso relativo disminuye (Figura 9.a) al tiempo que se incrementa el del mes de agosto. Tan importante resulta dicho proceso que en la parte central de Mallorca (Figura 9.a) el porcentaje de descargas registradas en el mes de agosto $(33,1 \%)$ es ligeramente superior a las del mes de septiembre $(32,7 \%)$, mientras que en el buffer más litoral, la concentración es de 12,5\% para el mes de agosto y 47,29\% para el mes de septiembre.

Además, en la parte central de la isla aparece un leve máximo secundario primaveral centrado en el mes de mayo, acumulando un 5,79\% de la actividad frente al 2,26\% del mes de abril y al 4,14\% del mes de junio.

En cambio, para la zona marítima (Figura 9.b) el máximo del mes de septiembre domina en todas las franjas, llegando incluso a superar ligeramente el $50 \%$ de la actividad anual, con una diferencia entre las distintas franjas marítimas muy poco significativa.

\subsubsection{Topografía}

Uno de los factores geográficos con mayor influencia en la actividad eléctrica es la topografía, que habitualmente presenta una correlación positiva con el número de descargas. Así sucede en la Península Ibérica, en la que los valores máximos que se registran en la zona de los Pirineos y Sistema Ibérico (Rivas Soriano et al 2005) y también en la zona alpina de Austria y Baviera, que presenta un óptimo de actividad entorno a los $1800 \mathrm{msnm}$ (Prinzet al 2011). De hecho, en el análisis global del área estudiada se ha podido constatar parcialmente este hecho (Figura 3).

A la vista del mapa, sorprende apreciar una relativa independencia entre distribución territorial del relieve y de la actividad tormentosa, a excepción de la citada coincidencia con la parte central y NE de la Serra de Tramuntana. Desde el punto de visto pluviométrico en Mallorca hay una relación directa entre la presencia de zonas montañosas y un incremento de precipitación, que se manifiesta en todas las áreas de relieve accidentado de la isla (Guijarro, 1986). En cambio, se puede observar como la presencia de áreas topográficamente elevadas como el extremo occidental de la Serra de Tramuntana, así como también el eje de las Serres de Llevant no tiene un reflejo en un incremento de la densidad de descargas elécticas.

El análisis pormenorizado de la distribución de las descargas por cotas altimétricas y distancias a la costa ofrece información adicional sobre la relación entre relieve y actividad tormentosa. Incidiendo en este aspecto, se ha detectado que para el buffer terrestre que incluye toda la superficie que diste menos de $5 \mathrm{~km}$ con la línea de costa la densidad de descargas se incrementa con la altitud (Tabla 1). Si el valor medio para esta área es de 2,49 descargas/ $\mathrm{km}^{2} / \mathrm{año}$, únicamente las zonas que se encuentran a una altitud inferior a $100 \mathrm{~m}$ presentan valores inferiores. Entre los 500 y los $1000 \mathrm{~m}$ el valor se dispara hasta las 3,79 descargas/ $\mathrm{km}^{2} /$ año, mientras que si subimos a cotas superiores a 1000m la densidad sube hasta las 8,25 descargas $/ \mathrm{km}^{2} / \mathrm{año}$. Comparando con los valores para toda la isla de Mallorca éstos son muy similares. 


\begin{tabular}{|l|c|c|}
\hline & \multicolumn{2}{|c|}{ Descargas eléctricas/km²/año } \\
\hline Altitud & $\mathbf{5 k m}$ & Mallorca \\
\hline $\mathbf{0 - 1 0 0}$ & 2,18 & 2,18 \\
\hline $\mathbf{1 0 0 - 2 0 0}$ & 2,52 & 2,41 \\
\hline $\mathbf{2 0 0 - 5 0 0}$ & 2,93 & 2,75 \\
\hline $\mathbf{5 0 0 - 1 0 0 0}$ & 3,79 & 3,93 \\
\hline$>\mathbf{1 0 0 0}$ & 8,25 & 7,87 \\
\hline Promedio & $\mathbf{2 , 4 9}$ & $\mathbf{2 , 4 6}$ \\
\hline
\end{tabular}

Fuente: Elaboración propia a partir de datos AEMET y modelo digital de elevaciones.

\subsubsection{Usos del suelo}

Un factor geográfico que potencialmente puede influir en la densidad de descargas son los usos del suelo. A partir del CorineLandCover 2006 se ha calculado la densidad de descargas para cada tipo de uso en la franja costera limitada por el buffer de $5 \mathrm{~km}$. En dicha área la densidad media es de 2,49 descargas $/ \mathrm{km}^{2} / \mathrm{año}$, y los datos presentan una gran homogeneidad entre las distintas zonas. Se han reunido en una tabla aquellos usos que presentan una mayor desviación (por arriba o por abajo) al valor medio (Tabla 2).

Aparecen dos usos con un valor superior a 4 descargas $/ \mathrm{km}^{2} / a n ̃ o$, que corresponden a láminas de agua y roquedo. El primer uso es muy minoritario, territorialmente restringido a los embalses, que se encuentran en cotas medias de la Serra de Tramuntana. El impacto de alguna descarga relativizado con la exigua superficie da como resultado esta aparente anomalía estadística. El roquedo, desprovisto de vegetación, puede corresponder tanto a áreas próximas a la línea de costa como a las cresterías calcáreas de las áreas montañosas, vinculadas consecuentemente con el factor topográfico. Igualmente, la influencia del relieve se manifiesta para el grupo de usos pastizales naturales y matorrales esclerófilos, particularmente notable en los primeros ya que las formaciones sabanoides de Ampelodesmos mauritanica únicos pastizales de la isla se concentran en las cumbres. (Bolós, 1996).

Un caso particular es la anómala afectación de las marismas (áreas topográficamente deprimidas) y sin arbolado, por tanto inicialmente poco propensas a recibir descargas eléctricas. La principal infraestructura de generación de energía eléctrica de la isla (central termoeléctrica des Murterar), se ubica casi en el centro de la principal área pantanosa de Mallorca (s'Albufera). La concentración de torres y líneas de alta tensión implícita a su alrededor conlleva un factor de atracción para la actividad eléctrica, que geográficamente ya es notable en la zona al estar inscrita en el máximo de actividad tormentosa general apreciado en el NE de la isla.

Las áreas que presentan los valores mínimos se corresponden con usos del suelo contrastados. Las vías de comunicación suelen seguir cotas topográficas bajas en relación a su 
entorno. Además de su poco peso significativo como área dado su carácter marcadamente lineal. Los cultivos anuales asociados con cultivos permanentes describen un uso agrario en dónde bajo la cubierta de almendro u otros frutales de secano se obtienen cosechas de cereales o leguminosas; esta práctica es especialmente abundante en sectores llanos del sur y el sureste de la isla ya descritas como poco proclives a recibir descargas por razones latitudinales y topográficas.

Tabla 2

DISTRIBUCIÓN DE LAS DESCARGAS ELÉCTRICAS EN FUNCIÓN DE LOS USOS DEL SUELO

\begin{tabular}{|l|c|}
\hline Uso del suelo & Descargas/km $\mathbf{2} / \mathbf{a n ̃ o}$ \\
\hline Láminas de agua & 4,64 \\
\hline Roquedo & 4,31 \\
\hline Matorrales esclerófilos & 3,53 \\
\hline Pastizales naturales & 3,44 \\
\hline Marismas & 3,40 \\
\hline Redes viarias, ferroviarias y terrenos asociados & 1,93 \\
\hline Cultivos anuales asociados con cultivos permanentes & 1,89 \\
\hline
\end{tabular}

Fuente: Elaboración propia a partir de datos AEMET y Corine Land Cover 2006

\section{CONCLUSIONES}

Mallorca y su entorno tiene una actividad tormentosa caracterizada por su gran variabilidad interanual, concentración temporal en el período de agosto a octubre, preferencia horaria disociada en las horas centrales de la jornada y primeras horas de la madrugada.

Estas características generales presentan diferencias de comportamiento según se trate de la isla o de la zona marítima circundante. Tales disimetrías no afectan sensiblemente a la densidad de descargas, sino que se centran en una distinta distribución horaria de las mismas. De hecho, es posible establecer una zonificación, diferenciado áreas a partir de la distribución horaria de las descargas:

1. Área con predominio de la actividad diurna: se localiza en el interior de Mallorca, a una distancia superior a $10 \mathrm{~km}$ respecto a la línea de costa. El porcentaje de actividad diurna es muy destacable, superior al 40\% para el período 10UTC a 14UTC.Además, se detectaun cambio de patrón en la actividad mensual, al incrementarse notablemente la misma en el mes de agosto, y la aparición de un leve máximo secundario en el mes de mayo.

2. Área con predominio de la actividad nocturna: las zonas marítimas separadas más de $10 \mathrm{~km}$ respecto a la costa muestran unos valores nocturnos ligeramente superiores a los diurnos, con acumulados de más del $30 \%$ de la actividad para el período de las 00UTC a las 04UTC.

3. Área de transición: se trata tanto de zona terrestre como de zona marítima donde conviven los dos máximos de actividad, sin que ninguno predomine sobre el otro. 
Se trata de un área en que se aprecia una influencia marítima en los primeros kilómetros interiores de Mallorca y una influencia terrestre en los primeros kilómetros marítimos.

El máximo de actividad diurna que se detecta coincidiendo con la zona central de la isla pudiera interpretarse como una consecuencia de un efecto microcontinental. Sin embargo esta afirmación no puede ser considerada concluyente ya que:

1. El patrón horario de la actividad en el centro de Mallorca (que se produce a mediodía) está claramente diferenciado del de las zonas continentales afines como la Península Ibérica, donde el máximo se da a media tarde (Rivas Soriano et al 2005).

2. Actividad mensual casi despreciable en los meses de junio y julio, coincidiendo con la máxima insolación. Este hecho supone que las condiciones térmicas del centro de Mallorca no son suficientemente extremas para generar por sí misma movimientos verticales potentes susceptibles de generar tormentas, como sí sucede en determinados ámbitos de la Península Ibérica (Rivas Soriano et al 2005) o en el estado de Georgia en EUA (Bentley y Stallins, 2005).

3. Lo que pudiera parecer ascendencia térmica se relaciona más bien con la convergencia de las brisas en el interior de Mallorca, ya que en ningún caso dista suficientemente de la franja costera para que la virazón diurna no influya. Por este motivo, en el mes de agosto con condiciones de ligera inestabilidad en capas medias la convergencia de brisas se transforma en un mecanismo efectivo de generación de actividad convectiva (Alomar, 2012;Alomar y Grimalt, 2009;Ramis, 1998). Asimismo debería tratarse el máximo secundario que aparece en el mes de mayo.

La distribución espacial de las descargas eléctricas se relaciona con la latitud ya que existe un gradiente norte sur en la densidad de descargas eléctricas, con los factores topográficos, con una densidad superior en las zonas más elevadas de Mallorca y con la línea teórica de convergencia de brisas. Sin embargo, su relación con determinados usos del suelo no es concluyente, ya que parece guardar más relación con la altitud en la que se encuentran dichos usos que en con los usos en sí.

Finalmente debe considerarse que en este artículo se trabaja con el número total de descargas y no con el de rayos. Ante la posibilidad de que un mismo rayo tenga distintas descargas, hecho que según algunos estudios se incrementa en la época cálida del año (Rivas Soriano et al 2005) el incremento en la actividad diurna y de mes de agosto que se produce en el interior de Mallorca podría deberse, al menos en parte, a un número mayor de descargas por rayo.

Trabajo financiado por el proyecto CGL2011-29263-C02-02 Estructura diaria y 10-minutal de la precipitación y su caracterización sinóptica objetiva en el mar Balear (Baleares)

Datos sobre descargas eléctricas facilitados por AEMET.

\section{AGRADECIMIENTOS}

Trabajo financiado por el proyecto CGL2011-29263-C02-02 Estructura diaria y 10-minutal de la precipitación y su caracterización sinóptica objetiva en el mar Balear (Baleares). Datos sobre descargas eléctricas facilitados por AEMET. 


\section{BIBLIOGRAFÍA}

ALOMAR, G. (2012): Geografia de la brisa marina a Mallorca. Universitat de les Illes Balears. Tesis Doctoral.

ALOMAR, G. y GRIMALT, M. (2009):«Tormentas y precipitaciones estivales en Mallorca. Microcontinentalidad y brisas marinas» en Congreso de Geógrafos Españoles. XXI. Ciudad Real. 1681-1690.

ALTARATZ, O., LEVIN, Z., YAIR, Y. y ZIV, B. (2003):«Lightning Activity over Land and Sea on the Eastern Coast of the Mediterranean». Monthly Weather Review $\mathrm{n}^{\mathbf{0}} 131$, 2060-2070.

BENTLEY, M.L. y STALLINS, J.A. (2005):«Climatology of cloud-to-ground lightning in Georgia, USA, 1992-2003». International Journal of Climatology. n 25, 1979-1996.

BLAKESLEE, R.J., MACH, D.M., BATEMAN, M.G. y BAILEY, J.C. (2012):«Seasonal variations in the lightning diürnal cycle andi mplications for the global electric circuit». Atmospheric Research. doi:10.1016/j.atmosres.2012.09.023 .

CHRISTIAN, H.J., BLAKESLEE, R.J., BOCCIPPIO, D.J., BOECK, W.L., BUECHLER, D.E., DRISCOLL, K.T., GOODMAN, S.J., HALL, J.M., KOSHAK, W.J., MACH, D.M. y STEWART, M.F., (2003): «Global frequency and Distribution of lighting as observed from space by the Optical Transient Detector». Journal of Geophysical Research.n ${ }^{\circ} 108$, ACL 4-1 - ACL 4-15.

CHRISTIAN, H.J., MCCOOK, M.A. «A Lightning Primer» Disponible en http://thunder. msfc.nasa.gov/primer/index.html.

GONZÁLEZ MÁRQUEZ J. (1996):«Distribución de las tormentas en Baleares». Boletín Mensual Climatológico. Islas Baleares. $\mathrm{n}^{\circ}$ 53, 121-124.

GUIJARRO, J.A. (1986): Contribución a la bioclimatologia de Baleares. Universitat de les Illes Balears. Resumen de Tesis Doctoral.

GUIJARRO, J.A. (2012): «Ciclo diario de la precipitación en las Islas Baleares». Territoris. $\mathrm{n}^{\circ} 8,117-128$.

GUIJARRO, J.A. y HEREDIA, M.A., (2004):«Climatología de las descargas eléctricas nube-tierra en las Islas Baleares». Revista de Climatología. nº4, 9-19.

LÓPEZ DÍAZ, J.A., PÉREZ PUEBLA, F. y ZANCO RODRÍGUEZ, C., (2012):«Tendencias y homogeneidad en las series de descargas eléctricas del periodo 2000-2011». Boletín Asociación Meteorológica Española. no 38, 34-39.

PASCUAL, R. y CALLADO, A. (2002): «Mesoanalysis of recurrent convergence zones in north-eastern Iberian Peninsula». Second European Conference on Radar Meteorology (ERAD) in conjunction with COST 717 mid-term seminar. Delft (Holanda), 8-22 noviembre 2002.

PÉREZ-PUEBLA, F., GUTIÉRREZ NÚÑEZ, J.M. y LÓPEZ RUIZ, F.J. (1999): «Análisis de las intensidades de los rayos registrados en la Península Ibérica en el período 19921995» en IV Simposio Nacional de Predicción del INM, Ministerio de Medio Ambiente, 577-580.

PETROVA, S., MITZEVA, R. y KOTRONI, V., (2012): «Summer-time lightning activity and its relation with precipitation: Diurnal variation over maritime, coastal and continental areas». Atmospheric Research. doi:10.1016/j.atmosres.2012.10.015. 
PRINZ, T., SPITZER, W., NEUWIRTH, C., SCHULZ, W., DIENDORFER, G. y KEUL, A. (2011): «GIS Analysis of Austrian-Bavarian cloud-to-ground lightning data» en 6th European Conference on Severe Storms (ECSS, 2011). Palma de Mallorca.Disponible en http://www.essl.org/ECSS/2011/programme/abstracts/99.pdf.

RAMIS, C. (1998): «L'embat a l'illa de Mallorca». Territoris. ${ }^{\circ}$ 1, 253-274.

RIVAS SORIANO, L., DE PABLO, F. y TOMAS, C., (2005): «Ten-year study of cloud-toground lightning activity in the Iberian Peninsula». Journal of Atmospheric and SolarTerrestrial Physics. $n^{\circ}$ 67, 1632-139.

RUIZ, M., TOMAS, M., MAS, C., SALVÀ, LL. y GRIMALT, M., (2012):«Climatología de las descargas eléctricas en Mallorca y su relación con las precipitaciones intensas (19942010)» en VIII Congreso Asociación Española de Climatologia. Salamanca, 951-960.

SEITY, Y., SOULA, S. y SAUVAGEOT, H. (2000):«Radar Observations and Lightning detection in coastal thunderstorms». Physics and chemistry of the earth. Part B, Hydrology, oceans and atmosphere. $\mathrm{n}^{\mathrm{o}} 25.1107-1110$.

WILLIAMS, E., CHAN, T. (2004):«Islands as miniature continents: Another look at the land-ocean lightning contrast». Journal of Geophysica lResearch. n 109, D16206 doi:10.1029/2003JD003833.

WILLIAMS, E., ROTHKIN, K., STEVENSON, D. y BOCCIPPIO, D. (2000):«Global lightning variations caused by changes in thunderstorm flash rateand by changes in the number of thunderstorms». Journal of Applied Meteorology. n 39, 2223-2230. 